\title{
Complete labelling of pneumococcal DNA-binding proteins with seleno-L-methionine
}

Fabián Lorenzo-Diaz ${ }^{1}$, Inmaculada Moreno-Córdoba ${ }^{2 \#}$, Manuel Espinosa ${ }^{2 *}$

${ }^{1}$ Departamento de Bioquímica, Microbiología, Biología Celular y Genética, Universidad de La Laguna, Santa Cruz de Tenerife, Spain; email: florenzo@ull.edu.es, and ${ }^{2}$ Centro de Investigaciones Biológicas, Consejo Superior de Investigaciones Científicas, Ramiro de Maeztu, 9, 28040 Madrid, Spain; emails: inmamoreno395@gmail.com; mespinosa@cib.csic.es

\#Present address: Department of Global Health, GlaxoSmithKline, Severo Ochoa, 2, 28760-Tres Cantos, Madrid, Spain.

*Email address: mespinosa@cib.csic.es 


\section{ABSTRACT}

Streptococcus pneumoniae is a pathogenic and opportunistic Gram-positive bacterium that is the leading cause of community-acquired respiratory diseases, varying from mild- to deathly- infections. The appearance of antibiotic-resistant isolates has prompted the search for novel strategies and targets to tackle the bacterial resistances. One of the most promising approaches is the structure-based knowledge of possible targets in conjunction with rational design and docking of inhibitors of the chosen targets. A useful technique that helps to solve protein structures is to label them with an amino acid derivative like seleno-methionine that facilitates tracing of some of the amino acid residues. We have chosen two pneumococcal DNA-binding proteins, namely the relaxase domain of MobM protein from plasmid pMV158, and the RelB-RelE antitoxin-toxin protein complex. Through several changes that improve substantially a previous protocol (Budisa et al., 1995), we have used seleno-L-methionine to incorporate selenium into the amino acid sequence of the selected proteins. We have achieved $100 \%$ labelling of the proteins and could demonstrate that the labelled proteins retained full activity as judged from the relaxation of supercoiled plasmid DNA and from gel-retardation assays.

Keywords: Streptococcus pneumoniae; protein purification; protein labelling; seleno-methionine; DNA-protein interactions

\footnotetext{
Abbreviations: COINs (Conjugation inhibitors), DTT (dithiothreitol), EMM (enriched minimal medium), EMSA (electrophoretic mobility shift assays), HGT (horizontal gene transfer), ICEs (integrative and conjugative elements), IPTG (isopropyl $\beta$-D-1-thiogalactopyranoside), MALDI Matrix-assisted laser desorption/ionization, OD (optical density), PAA (polyacrylamide), PAGE (polyacrylamide gel electrophoresis), RNAP (RNA polymerase), SeMet (seleno-methionine), SDS (sodium dodecyl sulphate), TAS (toxin-antitoxin systems), TOF (time of flying).
} 


\section{Introduction}

Streptococcus pneumoniae (the pneumococcus) is a Gram-positive pathogenic bacterium responsible for the death of about 1.5 million humans per year. The bacterium is especially lethal for children below 5 years, elderly people, and immunocompromised patients (Mandell et al., 2007). In addition to the deadly community-acquired pneumonia, the pneumococcus is the causal agent of a number of milder diseases, like meningitis, otitis media and sepsis, all of them requiring medium- to short-sick leaves with the concomitant loss of working hours and economic burden. Antibiotic treatments against pneumococcal and other lethal bacterial pathogens have resulted in the selection of bacteria with high levels of resistance ('the superbugs') to which there is an urgent need to find treatments alternative to the classical use of antibiotics (Bravo et al., 2018). Thus, it has been proposed that tackling pneumococcal diseases should consider approaches complementary to and/or different than antibiotic treatments (Chan et al., 2015). Among the possible strategies, two of them seem to be relevant because there are examples that can be taken as proofs of principle: i) inhibitors of bacterial conjugation (COINs), and ii) bacterial Toxin-Antitoxin systems (TAS) (Chan et al., 2015; Chan and Espinosa, 2016).

The use of COINs contemplates the search for molecules that are able to inhibit horizontal gene transfer of genetic elements conferring antibiotic resistance, like plasmids, and other mobile elements. Among those molecules, it has been shown that unsaturated fatty acids act as effective COINs (Fernandez-Lopez et al., 2005, García-Cazorla et al., 2018). Inhibition seems to be due to interference with the ATPase activity of the VirB11-type proteins that participate in the Type IV Secretion System protein complex (Grohmann et al., 2018). The exploitation of the toxin proteins from the bacterial TAS as targets for drug discovery, especially of type II (proteic) family, is the second strategy. Pioneer work showed that TAS are present in the majority of prokaryotes, but they are absent in eukaryotes (Pandey and Gerdes, 2005), and because of this, they have been considered as attractive molecules to be 
used as antibacterials (Hayes and Kędzierska, 2014, Kędzierska and Hayes, 2016, Mutschler and Meinhart, 2011). Type II TAS are usually organized as operons of two genes, the antitoxin preceding the toxin genes; whereas the toxin is a stable protein, the antitoxin is a labile protein mostly because of its unfolded nature (Ainelo et al., 2016, Kędzierska and Hayes, 2016). Under stressful conditions, the TAS are triggered and the antitoxin is prone to degradation by proteases, releasing the toxin to act as a poison to halt cell growth. The most promising approach to the use of TAS as antibacterials is based on the finding that short peptides can disrupt the strong T-A interactions, facilitating the use of these peptides as true antibacterials (Fernández-Bachiller et al., 2016, Lioy et al., 2010).

The two above approaches require that the three-dimensional structure of the proteins is known to design the proper antimicrobials. In the case of S. pneumoniae and its mobile elements, not very many protein structures with a known function have been determined so far and they include plasmid-encoded proteins (Boer et al., 2009, Espinosa, 2013, Gomis-Ruth et al., 1998, Pluta et al., 2017). This lack of knowledge could be attributed to the research on pneumococcus being more focussed on its epidemiology and management than on finding novel drug targets. However, recent approaches to solve the structure of important pneumococcal proteins have been reported (Gutiérrez-Fernández et al., 2016, Perez-Dorado et al., 2007, Rued et al., 2019). In many of these cases, determination of three-dimensional structures of the pneumococcal proteins has been aided by the use of derivatives in which replacement of amino acids lateral groups takes place. This has been shown to be especially useful when sulphur was substituted by selenium because this isomorphous replacement maintains the proteins with similar chemical properties. Thus, the use of selenomethionine (SeMet), and less frequently selenocysteine, has been one of the procedures of choice because of the incorporation of selenium into the proteins facilitates the determination of their structures by the use of the multiwavelength anomalous dispersion method (Budisa et al., 1995). In the present work, we have modified and updated the early seminal work from Huber's laboratory 
(Budisa et al., 1995), the use of which has allowed us to attain complete $(100 \%)$ labelling of pneumococcal DNA-binding proteins with SeMet. We have chosen the untagged MobMN199 from plasmid pMV158 (Lorenzo-Díaz et al., 2011) and the His-tagged RelBE protein complex from the pneumococcal TAs (Nieto et al., 2006). Further, we show that the SeMet-labelled proteins retained full activity as determined by plasmid DNA relaxation and band-shift experiments.

\section{Materials and Methods}

\subsection{Bacterial strains, plasmids, and DNA manipulations}

Strains and plasmids used are listed in Table 1. Escherichia coli strains were based in the DE3 lambda lysogen developed in Studier's laboratory (Studier and Moffatt, 1986, Studier et al., 1990) in which the RNA polymerase (RNAP) of bacteriophage T7 is cloned under the control of the lacUV5 promoter, inducible by isopropyl $\beta-D-1$-thiogalactopyranoside (IPTG), whereas the desired gene(s) is cloned in a plasmid under the control of the $\Phi 10$ promoter of phage T7. Induction with IPTG triggers the phage RNAP synthesis and, in turn, synthesis of the mRNA of the desired gene is also triggered.

The S. pneumoniae strain R6 is a noncapsulated derivative from the virulent strain D39 (Tettelin et al., 2001), and was used either for: i) isolation of total genomic DNA and PCR-amplification of a DNA region encompassing the relBE operon to clone it in the expression vector (Nieto et al., 2006), or ii) amplification of a 256-bp double-stranded DNA fragment that includes the promoter region, the transcription initiation site, and the Shine-Dalgarno sequences of the relBE operon, when functional assays were performed. The same pneumococcal strain harbouring plasmid pMV158 (Burdett, 1980) was used to prepare purified plasmid DNA by two consecutive $\mathrm{CsCl}$ gradients as reported (del Solar et al., 1987). Cloning of the truncated gene mobMN199 encoding the relaxase domain of the pMV158-encoded mobM gene have been detailed elsewhere (Lorenzo-Díaz et al., 2011). Similarly, 
cloning of the His-tagged pneumococcal relBE operon (formerly termed relBE2Spn) has been reported previously (Moreno-Córdoba et al., 2012).

\section{Table 1}

Bacterial strains and plasmids

\begin{tabular}{|c|c|c|c|c|}
\hline Strain & Genotype & Plasmid & Source of & Reference \\
\hline \multirow{2}{*}{$\begin{array}{c}\text { E. coli } \\
\text { BL21(DE3) }\end{array}$} & \multirow{2}{*}{$\begin{array}{c}\lambda \text { DE3 (lacl } \\
\text { lacUV5-T7 gene } \\
1 \text { ind1 sam7 } \\
\text { nin5) } \mathrm{F}^{-} d c m \\
\text { ompT } \\
\text { hsdS }\left(r_{\mathrm{B}}{ }^{-} m_{\mathrm{B}}{ }^{+}\right) \text {gal }\end{array}$} & pMobMN199 & $\begin{array}{l}\text { Unlabelled protein } \\
\text { MobMN199 }\end{array}$ & $\begin{array}{l}\text { (Lorenzo-Díaz et al., } \\
\text { 2011; Pluta et al., } \\
\text { 2017; Studier and } \\
\text { Moffatt, 1986) }\end{array}$ \\
\hline & & pET28relBE & $\begin{array}{l}\text { Unlabelled proteins } \\
\text { RelBRelEHis }_{6}\end{array}$ & $\begin{array}{c}\text { (Moreno-Córdoba et } \\
\text { al., 2012; Studier and } \\
\text { Moffatt, 1986) }\end{array}$ \\
\hline \multirow{2}{*}{$\begin{array}{c}\text { E. coli } \\
\text { B834(DE3) }\end{array}$} & \multirow{2}{*}{$\begin{array}{c}\lambda \text { DE3 (lacl } \\
\text { lacUV5-T7 gene } \\
\text { 1, ind1, sam7, } \\
\text { nin5) } \mathrm{F}^{-}, d c m, \\
\text { lon, ompT, } \\
\text { hsdS }\left(r_{\mathrm{B}}^{-} m_{\mathrm{B}}^{+}\right) \text {gal, } \\
\text { met }\end{array}$} & pMobMN199 & $\begin{array}{c}\text { SeMet-labelled } \\
\text { protein MobMN199 }\end{array}$ & $\begin{array}{l}\text { (Lorenzo-Díaz et al., } \\
\text { 2011; Pluta et al., } \\
\text { 2017; Studier and } \\
\text { Moffatt, 1986) }\end{array}$ \\
\hline & & pET28relBE & $\begin{array}{l}\text { SeMet-labelled } \\
\text { proteins } \\
\text { RelBRelEHis }_{6}\end{array}$ & $\begin{array}{l}\text { (Moreno-Córdoba et } \\
\text { al., 2012; Studier and } \\
\text { Moffatt, 1986) }\end{array}$ \\
\hline \multirow{2}{*}{$\begin{array}{c}\text { S. pneumoniae } \\
\text { R6 }\end{array}$} & & None & Genomic DNA & (Tettelin et al., 2001) \\
\hline & Wild type & pMV158 & $\begin{array}{c}\text { Plasmid pMV158 } \\
\text { DNA }\end{array}$ & $\begin{array}{l}\text { (Burdett, 1980; del } \\
\text { Solar et al., 1987) }\end{array}$ \\
\hline
\end{tabular}

\subsection{Bacterial growth conditions}

Pneumococcal cells were grown in the semi-defined medium AGCH (Lacks, 1968, Ruiz-Cruz et al., 2010) supplemented with sucrose, until middle exponential phase $\left(2-3 \times 10^{8}\right.$ cells $\left./ \mathrm{ml}\right)$. Cells were collected by centrifugation and treated as reported to prepare either total chromosomal DNA (López et al., 1982) or purified plasmid DNA. E. coli cells were grown in M9 medium that was prepared 10x (Maniatis et al., 1982) and that was enriched with mixture of vitamins (riboflavin, biotin, thiamine and pyridoxine at $10 \mu \mathrm{g} / \mathrm{ml}$ each, final concentration) and amino acids (except methionine; $40 \mu \mathrm{g} / \mathrm{ml}$, final concentration). Glucose $(20 \mathrm{mM}$, final concentration) was the carbon source used. When needed, methionine $(50 \mu \mathrm{g} / \mathrm{ml}$, 
final concentration) was added to this enriched minimal medium (EMM+Met). To prepare uniform pre-inocula, cells harbouring plasmids were inoculated into $25 \mathrm{ml}$ of EMM-Met, incubated at $37^{\circ} \mathrm{C}$ until mid exponential phase $\left(\sim 8 \times 10^{7}\right.$ cells $\left./ \mathrm{ml}\right)$ and centrifuged, washed with the same medium and concentrated ten times. Glycerol $(10 \%)$ was added and, after further $10 \mathrm{~min}$ incubation at $37^{\circ} \mathrm{C}, 25 \mu \mathrm{l}$ aliquots were prepared and stored at $-80^{\circ} \mathrm{C}$ until further use. Growth was followed by determination of the optical density of the cultures at $600 \mathrm{~nm}\left(\mathrm{OD}_{600}\right)$.

\subsection{Labelling proteins with SeMet and protein purification}

Pre-inocula $(10 \mu \mathrm{l})$ from the frozen culture samples (above) were inoculated into $5 \mathrm{ml}$ fresh $\mathrm{EMM}+$ Met and incubated at $37^{\circ} \mathrm{C}$ until $\mathrm{OD}_{600}$ reached $\sim 0.8$. Four $\mathrm{ml}$ of this culture was then diluted into $400 \mathrm{ml}$ of the same pre-warmed medium and incubation continued until the cultures reached the same $\mathrm{OD}_{600}$ (around $4.5 \mathrm{~h}$ ). Then, cells were collected by centrifugation, washed twice with EMM lacking methionine and resuspended into the original amount $(400 \mathrm{ml})$ of the same medium. To deplete the pool of internal methionine, cells were further incubated $30 \mathrm{~min}, 37^{\circ} \mathrm{C}$. Then, the culture was added to 3.6 I of pre-warmed EMM+SeMet $(50 \mu \mathrm{g} / \mathrm{ml})$, separated into $750-\mathrm{ml}$ portions and incubation continued at $37^{\circ} \mathrm{C}$. When the $\mathrm{OD}_{600}$ reached $\sim 0.5$, IPTG (final concentration $1 \mathrm{mM}$ ) was added and incubation continued $2 \mathrm{~h}$ more. Then, rifampicin (dissolved in dimethylsulfoxide, final concentration $100 \mu \mathrm{g} / \mathrm{ml}$ ) was added, and incubation continued $1.5 \mathrm{~h}$ more. Cells were harvested by centrifugation and washed with buffer A (MobMN199) or buffer C (RelB-RelE) (Table 2). Detailed purification protocols for the untagged MobMN199 (Lorenzo-Díaz et al., 2011) and of the His-tagged RelB-RelE(His)6 complex (Moreno-Córdoba et al., 2012) proteins are described in the Results Section.

\section{Table 2}

Buffer compositions 
A $20 \mathrm{mM}$ Tris-HCl pH 7.6, 1mM EDTA, 1mM dithiothreitol, 5\% MobMN199 purification glycerol, $300 \mathrm{mM} \mathrm{NaCl}$ (Affinity chromatography)

C $20 \mathrm{mM}$ Tris pH 8.0, 5\% ethylene glycol, $1 \mathrm{mM}$ RelB-RelE purification $\beta$-mercaptoethanol, $10 \mathrm{mM}$ imidazole, $500 \mathrm{mM} \mathrm{NaCl}$ (IMAC)

\begin{tabular}{ccc}
\hline S & $20 \mathrm{mM}$ Tris pH 7.6, $1 \mathrm{mM}$ EDTA, $5 \%$ ethylene glycol, $1 \mathrm{mM}$ & Gel-filtration \\
DTT, $500 \mathrm{mM} \mathrm{NaCl}$ & chromatography \\
\hline $\mathrm{M}$ & $20 \mathrm{mM}$ Tris pH 8.0, $1 \mathrm{mM}$ EDTA, $1 \mathrm{mM} \mathrm{DTT}, 10 \%$ glycerol, & EMSA \\
& $10 \mathrm{mg} / \mathrm{ml}$ heparin, $50 \mathrm{mM} \mathrm{NaCl}$ & \\
\hline
\end{tabular}

\subsection{Mass spectra analyses}

Matrix-assisted laser desorption/ionization (MALDI) experiments were performed on an Autoflex III MALDI-TOF-TOF instrument (Bruker Daltonics, Bremen, Germany) equipped with a smart-beam laser to measure the time of flying (TOF). The spectra were acquired using a laser power just above the ionization threshold. Samples were analyzed in the positive ion detection and delayed extraction linear mode. Typically, 1,000 laser shots were summed into a single mass spectrum. External calibration was performed using standard proteins (Sigma) namely insulin (5.8 kDa), cytochrome C (12.4 kDa), trypsinogen (23.9 kDa), carbonic anhydrase $(29 \mathrm{kDa})$, and protein $\mathrm{A}(44.6 \mathrm{kDa})$. The spectra covered the range from 2,000 to $30,000 \mathrm{Da}$.

\subsection{Computer analyses}

Predictions of secondary structures of the proteins were done by the use of PredictProtein (Rost et al., 2004), PSIPRED (Buchan and Jones, 2019; McGuffin and Jones, 2000), and Jpred (Cole et al., 2008) servers.

\subsection{Functional analyses of SeMet-labelled proteins}

Relaxation assays with unlabelled and SeMet-labelled MobMN199 were performed by incubation of supercoiled purified pMV158 plasmid DNA ( $8 \mathrm{nM})$ with 
$480 \mathrm{nM}$ protein in buffer $\mathrm{A}$ (Table 2), to which $15 \mathrm{mM} \mathrm{MnCl}_{2}$ was added. Incubation was at $30^{\circ} \mathrm{C}, 20 \mathrm{~min}$, and the reaction products were separated by electrophoresis on 1\% agarose gels as reported (Lorenzo-Díaz et al., 2011; Lorenzo-Díaz et al., 2018). Cleavage of covalently closed supercoiled DNA by the MobMN199 proteins resulted in generation of relaxed DNA. The efficiency of the relaxation reaction $\left(\eta_{R}\right)$ was calculated by the equation:

$$
\eta_{R}=\left[\left(F I_{R}-F I_{0}\right) / F I\right] \times 100
$$

where $\mathrm{FI}$ are the supercoiled molecules present in the DNA preparation, $F I_{R}$ indicates the relaxed molecules, and $\mathrm{FII}_{0}$ are the background values (FII forms already present in the MobM-untreated samples, most likely generated by mechanical shearing). In the case of the RelB-RelE protein-protein complex, functional assays were done by electrophoretic mobility shift assays (EMSA). To this end, $10 \mathrm{nM}$ of the 256-bp DNA fragment (that includes the promoter, transcription initiation site, and the Shine-Dalgarno sequences of the relBE pneumococcal operon), was incubated with different amounts of unlabelled or SeMet-labelled RelB-RelEHis 6 proteins $(0.2,0.4$ and $0.9 \mathrm{nM})$ in buffer M (Table 2). After 20 min at room temperature, samples were separated by electrophoresis on native $5 \%$ polyacrylamide (PAA) gels. In all cases, gels were stained with ethidium bromide and the DNA bands were visualized with the aid of a Gel-Doc documentation system (Bio-Rad Laboratories).

\section{Results and Discussion}

\subsection{Organization of the pneumococcal proteins}

MobM is the protein that initiates the conjugal transfer of plasmid pMV158 by cleavage of the phosphodiester bond at a specific di-nucleotide (5'-GpT-3') within the plasmid origin of transfer, oriT (Supplementary Figure S1A). The endonuclease activity of MobM is exerted on supercoiled plasmid DNA molecules (forms $\mathrm{FI}$ ) that are converted into relaxed forms (forms Fll; Guzmán and Espinosa, 1997). The 
native MobM is a prolate-ellipsoid dimer composed by two identical subunits of 494 residues per protomer (de Antonio et al., 2004), of which the first Met residue is removed after production (Lorenzo-Díaz et al., 2011). The protein has two distinct domains connected by a flexible region (Figure 1A). The $\mathrm{N}$-terminal moiety (around 200 amino acids) encompasses the DNA-binding and relaxase domain (Lorenzo-Díaz et al., 2011). The C-terminal moiety is mostly a-helical and contains: i) the dimerization domain which includes a putative Leu-zipper (Fernández-López et al., 2013); ii) the membrane-interaction region (de Antonio et al., 2004), and iii) probably the domain involved in interaction with the coupling protein involved in conjugal transfer (Fernández-López et al., 2013). Attempts at obtaining crystals using the native full-length MobM failed, probably due to the association of MobM with the host membrane (de Antonio et al., 2004). Thus, a truncated version of the protein that includes the first 199 residues harbouring the endonuclease-relaxase domain (MobMN199; Figure 1A) was designed, and the DNA region encoding this truncated protein was cloned into an expression vector (Table 1). Protein MobMN199 was, thus, the best candidate to achieve the three-dimensional structure of the MobM-relaxase domain in complex with its target DNA (Lorenzo-Díaz et al., 2011). Prediction of the secondary structure of MobMN199 (Figure 1B) showed an alternant distribution of $\alpha$-helices with $\beta$-strands, that is the $\alpha / \beta$-fold, which is found in many of the HUH endonucleases (Chandler et al., 2013). This prediction was confirmed by circular dichroism analyses (Lorenzo-Díaz et al., 2011) and, later on, when we could solve the structure of MobMN199 (Pluta et al., 2017). 


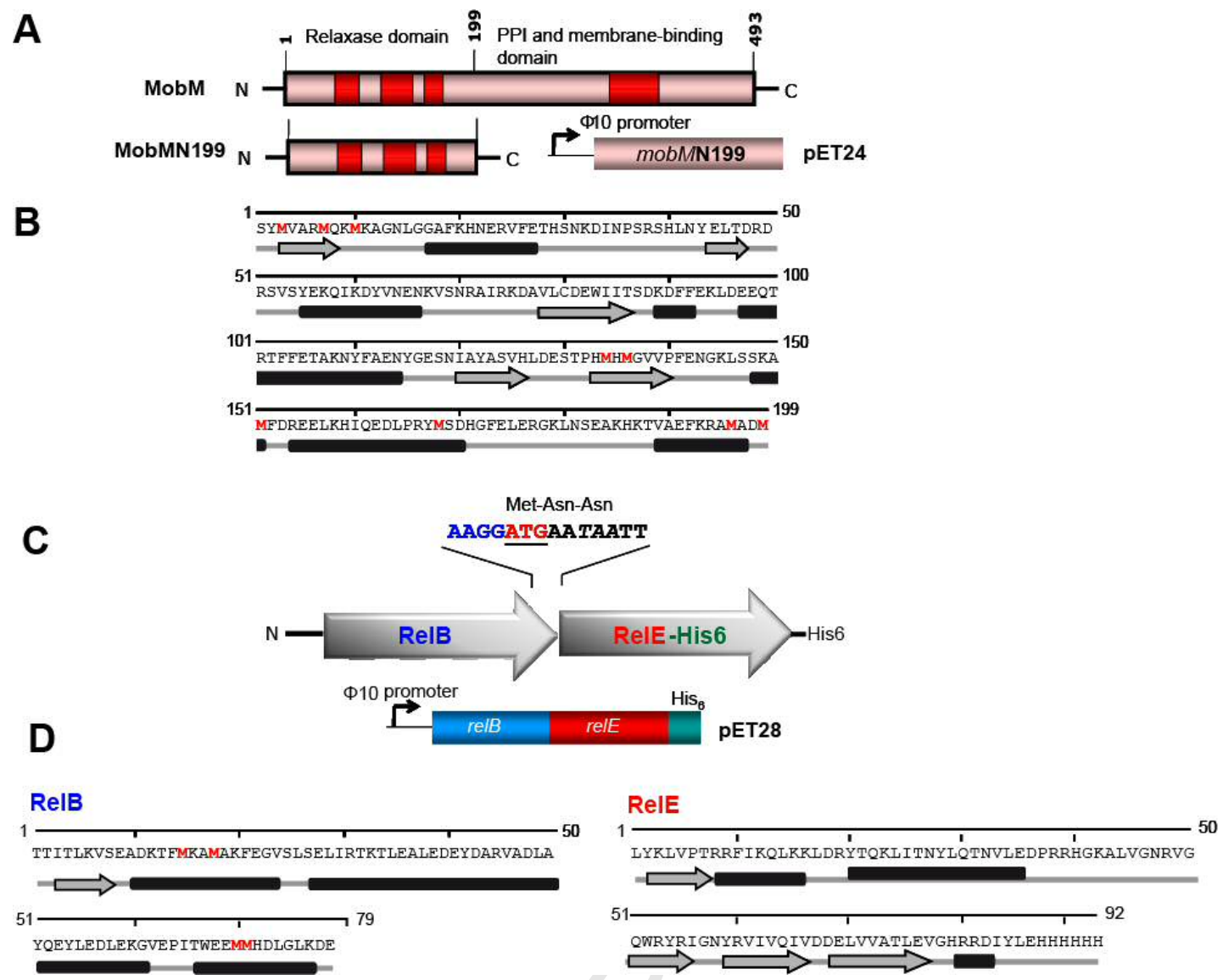

Figure 1: Organization (A, C), and predicted secondary structures (B, D) of the proteins analysed in this work. A. Protein MobM is encoded by plasmid pMV158 and contains two distinct regions: the $\mathrm{N}$-terminal domain harbours the relaxase domain (MobMN199), whereas the C-terminal domain is involved in protein-protein interactions and membrane association (Fernández-López et al., 2013; Lorenzo-Díaz et al., 2011). The genetic region encoding MobMN199 was cloned in the expression vector pET24 and the native domain was overexpressed, labelled with SeMet and purified (see Figure 2). B. The predicted secondary structure of MobMN199 indicated a distribution of $\alpha$-helices alternating with $\beta$-strands, the so-called $\alpha / \beta$-fold typical of many of the $\mathrm{HUH}$ endonucleases (Chandler et al., 2013). The structure of MobMN199 was later solved and corresponded to the prediction (Pluta et al., 2017). C. Schematic representation of the pneumococcal RelB (antitoxin, blue)-RelE (toxin, red) proteins. The termination codon of relB (TAA, italics) and the initiation codon of relE (ATG, in red) are indicated. The genes encoding these proteins were cloned into the expression vector pET28 which adds a $\mathrm{His}_{6}$ tag to the $\mathrm{C}$-terminal region of the toxin RelE (Moreno-Córdoba et al., 2012). D. The predicted secondary structure of RelB (left) suggested the existence of an N-terminal $\beta$-strand that could be incorporated into a $\beta$-sheet by interaction with another RelB molecule to fold as a dimer with a ribbon-helix-helix structure (Gomis-Ruth et al., 1998). All Met residues are marked in red; note that due to processing the $\mathrm{M} 1$ residue was always removed. Black boxes and arrows below the amino acid sequences correspond to predicted $\alpha$-helices and $\beta$-strands, respectively. 
In the case of the pneumococcal RelB-RelE proteins, the genetic structure of the intergenic region (Figure 1C) showed that the ATG start codon of relE (encoding the toxin) is placed three codons upstream of the termination (TAA) codon of relB (encoding the antitoxin), a situation indicative of translational coupling of both proteins. The operon was cloned into an expression vector that tags the $\mathrm{C}$-terminus of relE with six His residues. Concerning the secondary structure predictions of the proteins (Figure 1D), RelB would start with a $\beta$-strand followed by three $\alpha$-helices, a situation that resembles a protein with a ribbon-helix-helix structure (Gomis-Ruth et al., 1998), whereas RelE would appear to have a distribution of a-helices and $\beta$-strands indicative of a more complex structure. Circular dichroism studied supported these predictions (Moreno-Córdoba et al., 2012). Analytical ultracentrifugation and native mass spectrometry experiments indicated that the RelB-RelE complex could be a heterohexamer composed of four antitoxin and two toxin protomers (Moreno-Córdoba et al., 2012).

\subsection{Purification protocols of the SeMet-labelled proteins}

Purification of the SeMet MobMN199 and SeMet RelB-RelE complex was done by induction of $E$. coli strain B834(DE3) harbouring plasmid pMobMN199 or plasmid pET28relBE, respectively. Unlabelled proteins were purified in the same way but using the $E$. coli strain BL21(DE3) as the host; detailed protocols for the purification of these latter proteins have been published elsewhere (Lorenzo-Díaz et al., 2011; Moreno-Córdoba et al., 2012). We have found several advantages of the present method over the previously published one (Budisa et al., 1995). Firstly, the plasmid vectors used here carry a gene encoding resistance to kanamycin rather than the previously used vectors encoding ampicillin-resistance (Budisa et al., 1995). The former marker has advantages because secretion of $\beta$-lactamase by the plasmid-containing cells facilitates the overgrowth of plasmid-free cells that do not encode the gene(s) of interest (Studier and Moffatt, 1986; Studier et al., 1990). This "satellite" overgrowth is even more frequent when very saturated cultures are used 
(Budisa et al., 1995). Secondly, reduction in the final protein yield would also occur after long periods of IPTG-induction of the cultures, since plasmid-encoding cells should reduce or stop their growth after induction (Studier and Moffatt, 1986); we have found that 2-3 $\mathrm{h}$ induction periods are sufficient for an optimal protein yield (Gomis-Ruth et al., 1998; Lorenzo-Díaz et al., 2011; Moreno-Córdoba et al., 2012). And thirdly, a further advantage of the method presented here is the use of inhibitors of the E. coli RNAP, like rifampicin, because the phage T7 RNAP only recognizes its own promoters and is insensitive to rifampicin; thus, addition of the drug will stop transcription from any of the $E$. coli promoters, and only the $T 7$ promoters will be active (Studier and Moffatt, 1986).

To purify the pneumococcal proteins, cultures from the frozen inocula were diluted in $\mathrm{EMM}$ medium and grown at $37^{\circ} \mathrm{C}$. At $\mathrm{OD}_{600} \sim 0.5$, cells were IPTG-induced and treated with rifampicin (see Methods). At the end of the incubation period, cells were centrifuged, washed twice, and suspended (20 times concentrated) in buffer A (MobMN199) or C (RelB-RelE) to which two tablets of a protease inhibitor cocktail (Complete EDTA-free; Roche) were added. The cell paste was passed twice through a French pressure cell and the cell lysates were cleared by two centrifugation steps: i) low-speed to remove unbroken cells and cell debris, and ii) high speed to remove any precipitate. We have found that disruption of the cells by the use of a French-pressure device gives higher yields of active protein than many other widespread mechanical procedures (sonication, manual grinding, or bead-beating). 
A

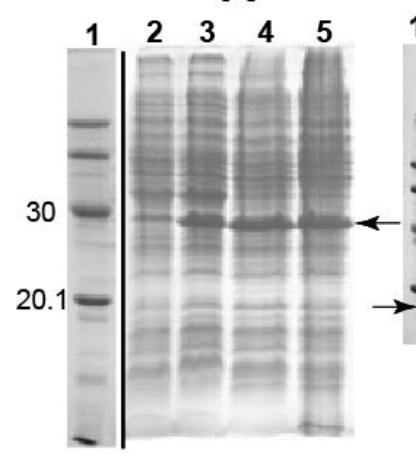

B

1

D
1

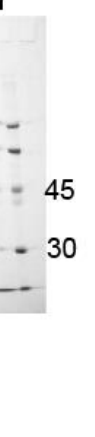

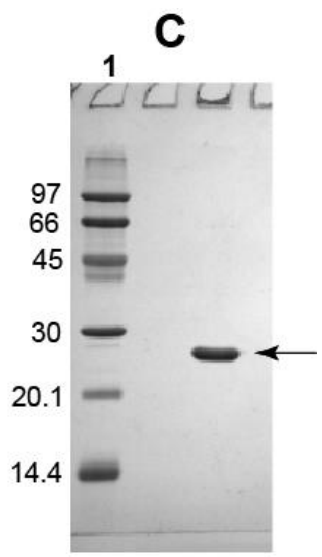

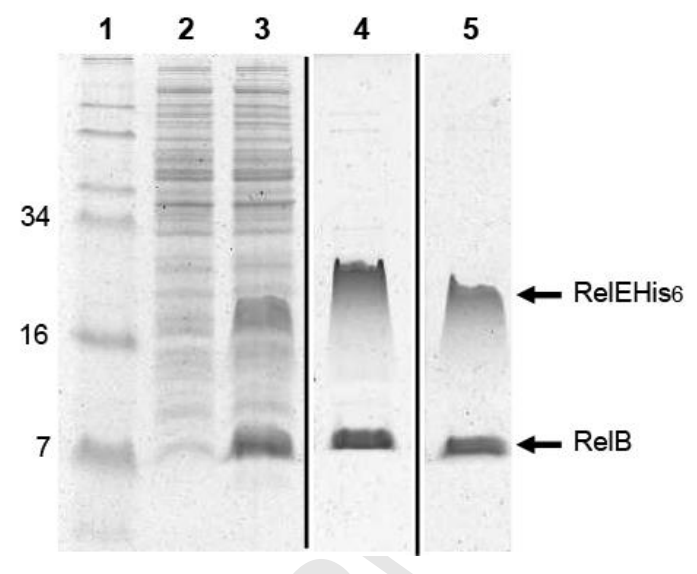

Figure 2: Purification stages of SeMet-labelled proteins. A-C: Cells harbouring the plasmid encoding mobMN199 were grown in SeMet-containing medium and the different purification stages were analyzed by electrophoresis on 15\% SDS-Tris-glycine PAA gels. (A) Samples shown were from: uninduced cultures (lane 2); cultures induced with IPTG and rifampicin (lane 3); supernatant after PEI precipitation (lane 4), and supernatant of the ammonium sulphate precipitation step after dialysis against buffer $A$ (lane 5 ). This latter fraction was loaded onto a heparin-agarose column and the retained proteins were eluted by a $0.3-0.8 \mathrm{M} \mathrm{NaCl}$ gradient $(B)$ as reported (Lorenzo-Díaz et al., 2011). Panel $\mathbf{C}$ shows the final purified MobMN199 protein. The yield of the purified protein was about $2 \mathrm{mg} / \mathrm{l}$. Lanes 1 in all the panels show the molecular weight standards with their mass $(\mathrm{kDa})$ indicated. D: Purification of RelB-RelEHis 6 proteins. Cells harbouring the plasmid encoding the relBE operon were grown in SeMet-containing medium, and the different purification stages were analyzed by electrophoresis on $16 \%$ SDS-Tricine-PAA gels. Proteins were detected by staining with Bio-safe Coomassie (BioRad Laboratories). Samples in the gels were: lane 1, molecular weight standard (SeeBlue Plus2, Invitrogen); lanes 2 and 3, total cell extracts from uninduced and induced cultures, respectively; lane 4, fractions from the eluted samples from the nickel column, and lane 5, purified proteins after gel filtration. Relevant protein positions are indicated. Migration of the two proteins of the complex was anomalous and due to their isoelectric points (Moreno-Córdoba et al., 2012).

In the case of MobMN199, the supernatant was treated with $0.2 \%(\mathrm{v} / \mathrm{v})$ polyethyleneimine (Sigma) to precipitate nucleic acids. Proteins in the supernatant were precipitated at $70 \%(\mathrm{w} / \mathrm{v})$ ammonium sulphate saturation. The proteins in the 
precipitate were collected by centrifugation and the pellet was dissolved in Buffer A (Figure 2A). After dialysis against the same buffer, the sample was loaded onto a $100-\mathrm{ml}$ heparin-agarose (BioRad) column (flow rate of $50 \mathrm{ml} / \mathrm{h}$ ). After washing with 5-column volumes of the same buffer, a $400-\mathrm{ml} 0.3-0.8 \mathrm{M} \mathrm{NaCl}$ gradient was applied to elute the proteins retained. Fractions were analyzed by 15\% SDS-Tris-glycine polyacrylamide gel electrophoresis (SDS-PAGE) followed by staining with Bio-safe Coomassie (BioRad Laboratories) (Figure 2B). Fractions containing the peak of MobMN199 were pooled, dialysed against Buffer A containing $500 \mathrm{mM} \mathrm{NaCl}$, and concentrated by filtering through $3 \mathrm{kDa}$ cut-off membranes (Pall) until the sample volume reached $1 \mathrm{ml}$. The protein sample was next automatically injected at 0.5 $\mathrm{ml} / \mathrm{min}$ onto a HiLoad Superdex 200 gel-filtration column (Amersham) and subjected to fast-pressure liquid chromatography (FPLC; Biologic DuoFlow from BioRad). Fractions containing pure MobMN199 protein ( $>98 \%$ ) were pooled and concentrated until the final concentration was $5 \mathrm{mg} / \mathrm{ml}$ protein (Figure 2C).

In the case of RelB-RelE, the cleared cell lysate was loaded onto a nickel column (His-select Nickel Affinity Gel, Sigma). After washing with buffer C, proteins were eluted in the same buffer supplemented with $250 \mathrm{mM}$ imidazol. Fractions were analysed by $16 \%$ SDS-Tris-glycine PAGE and proteins were detected by staining with Bio-safe Coomassie (BioRad Laboratories). Fractions containing the peaks of the desired proteins were pooled, dialyzed against buffer $S$ and applied to a gel filtration column (Superdex 200 XK16/60 column, Amersham Pharmacia Biotech). Fractions were analyzed by gel electrophoresis (Figure 2D), and we found that the $\operatorname{Re} \mathrm{E}(\mathrm{His})_{6}$ protein exhibited an anomalous migration $\left(\mathrm{M}_{\mathrm{r}} \sim 18000\right)$ higher than the theoretical value $\left(\mathrm{M}_{\mathrm{r}}\right.$ 11500). This discrepancy could be explained because RelE has a high isoelectric point $(\mathrm{pl}=10.27)$ and the concentration of SDS used in the gels $(0.5 \%)$ was not enough to provide a near-uniform negative charge to the protein. Fractions containing the desired proteins were pooled and concentrated by filtration through $3 \mathrm{kDa}$ cut-off filters (Pall). The purified proteins were stored at $-80^{\circ} \mathrm{C}$ where they remained active for at least one year. 


\subsection{MALDI-TOF Molecular Weight Determinations}

To assess the degree of SeMet labelling of the pneumococcal proteins, we determined the molecular weight of the unlabelled and labelled proteins by the employment of mass spectra experiments. The results are depicted in Figure 3 and they are summarized in Table 3. MALDI-TOF spectra of MobMN199 unlabelled (Figure $3 \mathrm{~A}$ ) or SeMet-labelled (Figure 3B) showed the existence of a major peak exhibiting molecular weights of 23,128.1 Da and 23,551.3 Da, respectively. The difference between both values was of $423.2 \mathrm{Da}$, which is consistent with the calculated theoretical value of MobMN199 protomers in which all the 9 Met residues (Met1 was processed) were substituted by SeMet ones. Thus, the efficiency of labelling was of $100 \%$.

In the case of RelB proteins, unlabelled or labelled, two major peaks were detected, the main one corresponding to RelB lacking M1, and a minor one pertaining to the full RelB (Figure 3C). A similar finding was observed for RelE, but in this case, the main peak corresponded to the protein lacking the first three residues (M1, N2, and N3), whereas the second minor peak could be assigned to the entire RelE (Figure 3D). Again, the efficiency of labelling was of $100 \%$. 

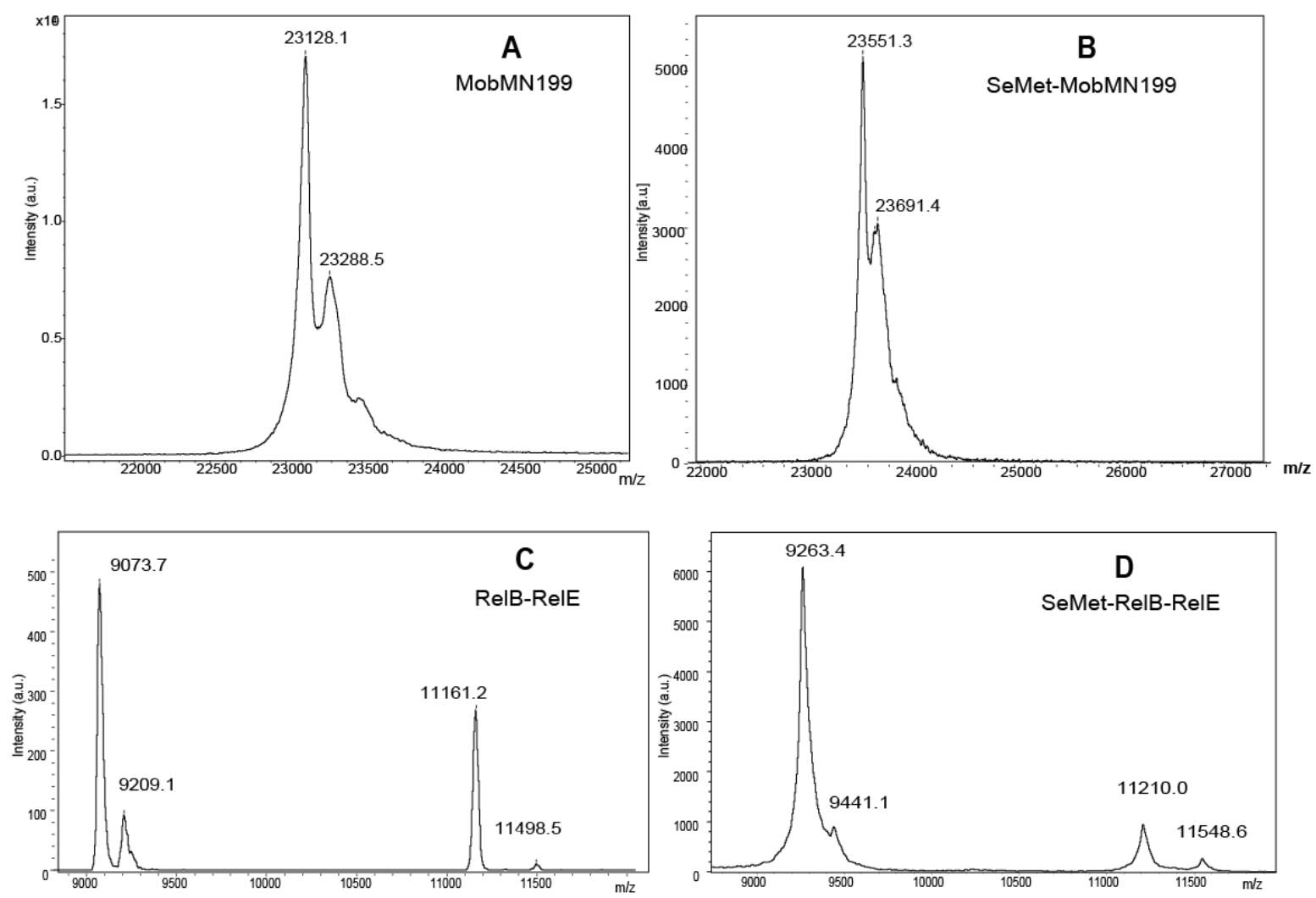

Figure 3: MALDI-TOF mass spectrometry of the pneumococcal DNA-binding proteins. Proteins analyzed were: MobMN198 (A, B), and RelB-RelE toxin-antitoxin proteins (C, D), unlabelled (A, C) and SeMet-labelled (B, D). The spectra and masses of the different molecules identified are indicated. The first Met residue of MobMN199 was processed, thereby leaving a 198-amino acid protein (MobMN198) containing 9 Met residues. Similarly, the first Met of RelB was removed and the resulting protein has 4 Met residues. In the case of RelE, most of the synthesized protein lacks the first three residues (Met-Asn-Asn), and the resulting protein has no Met residues.

Table 3

Expected and MALDI-TOF determined molecular weights of the SeMet-labelled pneumococcal proteins.

\begin{tabular}{llll}
\hline Features / Protein & MobMN199 & RelB & RelEHis $_{6}$ \\
\hline Predicted MW of unlabelled protomer (Da) & 23129.8 & $9205^{\mathrm{a}}$ & 11505.3 \\
\hline Determined MW of unlabelled protomer (Da) & 23128.1 & 9073.7 & $111612^{\mathrm{b}}$ \\
\hline Number of Met residues $^{\mathrm{a}}$ & 9 & 4 & 0 \\
\hline Theoretical MW of SeMet-labelled protomer $(\mathrm{Da})$ & 23551.9 & 9262 & $11552^{\mathrm{b}}$ \\
\hline Determined MW of SeMet-labelled protomer (Da) & 23551.3 & 9263.4 & $11210^{\mathrm{b}}$ \\
\hline Percent incorporation & $\mathbf{1 0 0}$ & $\mathbf{1 0 0}$ & --- $^{\mathrm{c}}$ \\
\hline
\end{tabular}




\footnotetext{
${ }^{a}$ The first Met residue of MobM and of RelB was removed by processing, as determined by N-terminal sequencing of the proteins (Fernández-López et al., 2013; Moreno-Córdoba et al., 2012).

${ }^{b}$ The vast majority of the protein lacked the first three amino acid residues (M1, N2, and N3) as previously determined (Moreno-Córdoba et al., 2012).

${ }^{\mathrm{c}}$ The percent incorporation could not be determined due to lack of any Met residue of the majority of the protein.
}

\subsection{Functional Assays}

To determine whether the SeMet-labelled proteins retained full activity, their interactions with substrate DNA were assayed. MobMN199 harbours the relaxase domain of the parental protein (Lorenzo-Díaz et al., 2011) and thus, the truncated version is able to relax cognate supercoiled DNA as efficiently as the full-length MobM. We tested the activity of the SeMet-MobMN199 on CsCl-purified pMV158 DNA under standard conditions (Figure 4A). Briefly, 8 nM supercoiled pMV158 DNA was incubated (lanes 2 and 3) or not (lane 1) with $480 \mathrm{nM}$ of unlabelled (lane 2) or SeMet-labelled (lane 3) MobMN199 in buffer A (Table 2) containing $15 \mathrm{mM} \mathrm{MnCl} 2$ (final concentration). After $20 \mathrm{~min}$ incubation at $30^{\circ} \mathrm{C}$, the reaction products were separated by electrophoresis on $1 \%$ agarose gels and stained with ethidium bromide. The results showed that the amount of forms FII (relaxed DNA molecules) generated by both proteins was roughly the same, an amount of $65 \%$ of relaxed FII forms derived from the supercoiled FI substrate, indicating that the cleavage reaction mediated by MobM was independent on whether the protein has its Met residues substituted or not by SeMet. 
A

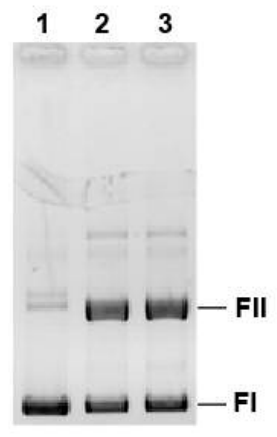

B

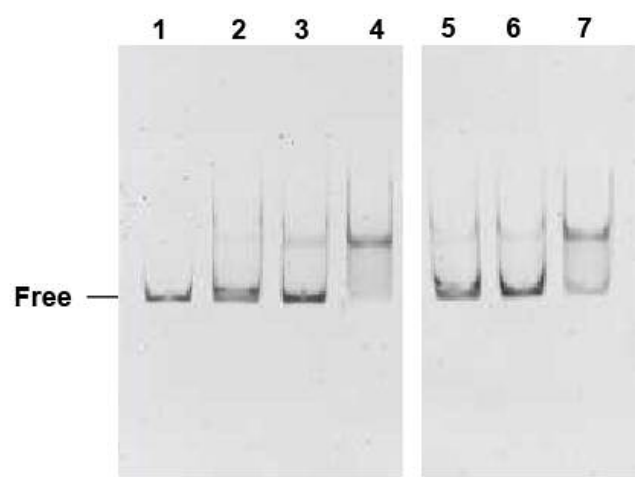

Figure 4: Functional assays of the SeMet-labelled proteins. (A). MobMN198 has endonucleolytic nicking-closing activity on supercoiled plasmid DNA molecules (Forms $\mathrm{FI}$ ) that are converted into relaxed molecules (Forms FII). Lanes shown in the gel are: 1, no protein, 2 unlabelled MobMN199, and 3, SetMet-labelled MobM. The weak band above relaxed forms FII has been observed before and might correspond to relaxed DNA dimers that are molecules insensitive to MobM-cleavage (Lorenzo-Díaz et al., 2011; Lorenzo-Díaz et al., 2018). (B). RelB-RelE protein complex has high affinity to bind linear double-stranded DNA containing its target, and no differences were found between the unlabelled (lanes 2-4) and SeMet-labelled proteins (lanes 5-7); lane 1, no protein was added. The amount of DNA used was $10 \mathrm{nM}$, whereas the proteins were used at 0.2 (lanes 2 and 5), 0.4 (lanes 3 and 6), and $0.9 \mathrm{nM}$ (lanes 4 and 7 ).

In the case of the RelB-RelE pneumococcal protein complex, the antitoxin RelB has a moderate DNA-binding affinity that is augmented by the toxin RelE, which acts as a co-repressor of the synthesis of both proteins (Moreno-Córdoba et al., 2012; Nieto et al., 2006). The DNA-binding ability of the RelB-RelE complex was tested by EMSA assays (Figure 4B), using as substrate a double-stranded 256-bp fragment containing the RelB-RelE target (Moreno-Córdoba et al., 2012). The results showed that the free DNA (Figure 4B, lane 1) molecules were retarded to generate a main protein-DNA complex that was dependent on the protein concentration used, but independent of whether the proteins were unlabelled (lanes 2-4) or labelled with SeMet (lanes 5-7).

\section{Conclusions}

The results presented here represent a substantial optimization of previous methods (Budisa et al., 1995) that has allowed us to achieve 100\% labelling of pneumococcal 
DNA-binding proteins with SeMet. The advantages of our procedure relies on: i) the marker of the plasmid vector (kanamycin rather than ampicillin) thus avoiding the outgrowth of plasmid-free cells usually associated to the latter marker; ii) the preparation of uniform pre-inocula that leads to reproducible growth of the cultures; iii) the time of IPTG-induction, which has been substantially reduced (from $8 \mathrm{~h}$ or more to $2 \mathrm{~h}$ ); iv) the reduction in the density of the cultures that allowed us to reduce the time devoted to preparation of the samples for protein purification, and $v$ ) the use of rifampicin to inhibit synthesis of E. coli mRNAs and that directs the host machinery to the synthesis of the phage T7-directed mRNA synthesis. Two pneumococcal protein variants were chosen: untagged (MobMN199) and His-tagged (RelB-RelEHis 6 ) proteins, demonstrating the applicability of the method, in which $100 \%$ efficiency of labelling was attained. Further, the SeMet-labelled proteins were shown to retain full activity as judged by DNA relaxation and EMSA experiments and comparison of the unlabelled and labelled proteins.

The structure of MobMN199 has been solved with the aid of SeMet-labelled protein (Pluta et al., 2017), whereas that of the RelB-RelE complex is being finished at present (unpublished results). Discovery of novel antibacterials nowadays is less focussed in testing libraries of compounds than it used to be, and drug discovery is strongly assisted by the use of known structures of the target. Thus, molecular docking and structure-based designs are the favourite methods of choice, when feasible (Cicaloni et al., 2019; Lee et al., 2019). To achieve these goals it is essential the cooperation between molecular microbiologists and structure-based laboratories.

\section{Supplementary data to this article can be found online at}

Acknowledgements: Thanks are due to Concha Nieto, Alicia Bravo, and Cris Fernández-López for helpful discussions and suggestions, and to our crystallographer colleagues (Miquel Coll's group, IBM-Barcelona, Spain) for discussions along the crystallization experiments. 
Author Contributions: All authors designed the experiments, which were performed by F.L-D. and

I.M-C. M.E. analyzed the results and wrote the first draft, which was corrected by all authors.

Funding: No funds were available at the time of submission

Declarations of interest: none.

Conflicts of Interest: The authors declare no conflict of interest.

\section{References}

Ainelo, A., Tamman, H., Leppik, M., Remme, J., Hõrak, R., 2016. The toxin GraT inhibits ribosome biogenesis. Mol. Microbiol. 100, 719-734.

Boer, D.R., Ruíz-Masó, J.A., López-Blanco, J.R., Blanco, A.G., Vives-Llàcer, M., Chacón, P., Usón, I., Gomis-Rüth, F.X., Espinosa, M., Llorca, O., del Solar, G., Coll, M., 2009. Plasmid replication initiator RepB forms a hexamer reminiscent of ring helicases and has mobile nuclease domains. EMBO J. 28, 1666-1678.

Bravo, A., Ruiz-Cruz, S., Alkorta, I., Espinosa, M., 2018. When humans met superbugs: strategies to tackle bacterial resistances to antibiotics. Biomol. Concepts. 9, 216-226.

Buchan, D.W.A., Jones, D.T., 2019. The PSIPRED Protein Analysis Workbench: 20 years on. Nucleic Acids Res. 47, W402-W407.

Budisa, N., Steipe, B., Demange, P., Eckerskorn, C., Kellermann, J., Huber, R., 1995. High-level biosynthetic substitution of methionine in proteins by its analogs 2-aminohexanoic acid, selenomethionine, telluromethionine and ethionine in Escherichia coli. Eur. J. Biochem. 230, 788-796.

Burdett, V., 1980. Identification of tetracycline-resistant R-plasmids in Streptococcus agalactiae (group B). Antimicrob Agents Chemother. 18, 753 - 760.

Cicaloni, V., Trezza, A., Pettini, F., Spiga, O., 2019. Applications of in silico methods for design and development of drugs targeting protein-protein interactions. Curr. Topics Med. Chem. 19, 534-554.

Cole, C., Barber, J., Barton, G., 2008. The Jpred 3 secondary structure prediction server. Nucleic Acids Res. 36, W197 - W201.

Chan, W.T., Balsa, D., Espinosa, M., 2015. One cannot rule them all: Are bacterial toxins-antitoxins druggable? FEMS Microbiol. Rev. . 39, 522-540.

Chan, W.T., Espinosa, M., 2016. The antibacterials that have yet to be found, Atlas of Science.

Chandler, M., Cruz, F., Dyda, F., Hickman, A.B., Moncalian, G., Ton-Hoang, B., 2013. Breaking and joining single-stranded DNA: the HUH endonuclease superfamily. Nat Rev Microbiol. 11, 525-538.

de Antonio, C., Farias, M.E., de Lacoba, M.G., Espinosa, M., 2004. Features of the plasmid pMV158-encoded MobM, a protein involved in its mobilization. J. Mol. Biol. 335, 733-743.

del Solar, G., Díaz, R., Espinosa, M., 1987. Replication of the streptococcal plasmid pMV158 and derivatives in cell-free extracts of Escherichia coli. Mol. Gen. Genet. 206, 428-435. 
Espinosa, M., 2013. Plasmids as models to study macromolecular interactions: the pMV158 paradigm. Res. Microbiol. 164, 199-204.

Fernández-Bachiller, M., Brzozowska, I., Odolczyk, N., Zielenkiewicz, U., Zielenkiewicz, P., Rademann, J., 2016. Mapping protein-protein interactions of the resistance-related bacterial Zeta toxin-Epsilon antitoxin complex $(\varepsilon 2 \zeta 2)$ with high affinity peptide ligands using fluorescence polarization. Toxins. 8, 222.

Fernández-López, C., Lorenzo-Díaz, F., Pérez-Luque, R., Rodríguez-González, L., Boer, R., Lurz, R., Bravo, A., Coll, M., Espinosa, M., 2013. Nicking activity of the pMV158 MobM relaxase on cognate and heterologous origins of transfer. Plasmid. 70, 120-130.

Fernandez-Lopez, R., Machon, C., Longshaw, C.M., Martin, S., Molin, S., Zechner, E.L., Espinosa, M., Lanka, E., de la, C., F., 2005. Unsaturated fatty acids are inhibitors of bacterial conjugation. Microbiology. 151, 3517-3526.

García-Cazorla, Y., Getino, M., Sanabria-Ríos, D.J., Carballeira, N.M., de la Cruz, F., Arechaga, I., Cabezón, E., 2018. Conjugation inhibitors compete with palmitic acid for binding to the conjugative traffic ATPase TrwD, providing a mechanism to inhibit bacterial conjugation. J. Biol. Chem. 293, 16923-16930.

Gomis-Ruth, F.X., Sola, M., Acebo, P., Parraga, A., Guasch, A., Eritja, R., Gonzalez, A., Espinosa, M., del Solar, G., Coll, M., 1998. The structure of plasmid-encoded transcriptional repressor CopG unliganded and bound to its operator. EMBO J. 17, 7404-7415.

Grohmann, E., Christie, P.J., Waksman, G., Backert, S., 2018. Type IV secretion in Gram-negative and Gram-positive bacteria. Mol. Microbiol. 107, 455-471.

Gutiérrez-Fernández, J., Saleh, M., Alcorlo, M., Gómez-Mejía, A., Pantoja-Uceda, D., Treviño, M.A., Voß, F., Abdullah, M.R., Galán-Bartual, S., Seinen, J., Sánchez-Murcia, P.A., Gago, F., Bruix, M., Hammerschmidt, S., Hermoso, J.A., 2016. Modular architecture and unique teichoic acid recognition features of choline-binding protein $\mathrm{L}(\mathrm{CbpL})$ contributing to pneumococcal pathogenesis. Sci. Rep. 6, 38094.

Guzmán, L.M., Espinosa, M., 1997. The mobilization protein, MobM, of the streptococcal plasmid pMV158 specifically cleaves supercoiled DNA at the plasmid oriT. J. Mol. Biol. 266, 688-702.

Hayes, F., Kędzierska, B., 2014. Regulating toxin-antitoxin expression: Controlled detonation of intracellular molecular timebombs. Toxins. 6, 337-358.

Kędzierska, B., Hayes, F., 2016. Emerging roles of Toxin-Antitoxin modules in bacterial pathogenesis. Molecules. 21, 790.

Kędzierska, B., Hayes, F., 2016. Transcriptional control of Toxin-Antitoxin expression: keeping toxins under wraps until the time is right, Stress and Environmental Regulation of Gene Expression and Adaptation in Bacteria, John Wiley \& Sons, Inc., pp. 463-472.

Lacks, S., 1968. Genetic regulation of maltosaccharide utilization in Pneumococcus. Genetics. 60, 685-706.

Lee, A.C.-L., Harris, J.L., Khanna, K.K., Hong, J.-H., 2019. A Comprehensive review on current advances in peptide drug development and design. Int. J. Mol. Sci. 20, 2383.

Lioy, V.S., Rey, O., Balsa, D., Pellicer, T., Alonso, J.C., 2010. A toxin-antitoxin module as a target for antimicrobial development Plasmid. 63, 31-39.

López, P., Espinosa, M., Stassi, D.L., Lacks, S.A., 1982. Facilitation of plasmid transfer in Streptococcus pneumoniae by chromosomal homology. J. Bacteriol. 150, 692-701. 
Lorenzo-Díaz, F., Dostál, L., Coll, M., Schildbach, J.F., Menendez, M., Espinosa, M., 2011. The MobM-relaxase domain of plasmid pMV158: thermal stability and activity upon $\mathrm{Mn}^{2+}$-and DNA specific-binding. Nucleic Acids Res. 39, 4315-4329.

Lorenzo-Díaz, F., Fernández-López, C., Guillén-Guío, B., Bravo, A., Espinosa, M., 2018. Relaxase MobM induces a molecular switch at its cognate origin of transfer. Front. Mol. Biosci. 5.

Mandell, L.A., Wunderink, R.G., Anzueto, A., Bartlett, J.G., Campbell, G.D., Dean, N.C., Dowell, S.F., File, T.M., Jr, Musher, D.M., Niederman, M.S., Torres, A., Whitney, C.G., 2007. Infectious Diseases Society of America/American Thoracic Society consensus guidelines on the management of community-acquired pneumonia in adults. Clin. Infect. Dis. 44, S27-72.

Maniatis, T., Fritsch, E.F., Sambrook, J., 1982. Molecular cloning: a laboratory manual, Cold Spring Harbor Laboratory Press, New York.

McGuffin, B.K., D.T., J., 2000. The PSIPRED protein structure prediction server. Bioinformatics. 16, 404-405.

Moreno-Córdoba, I., Diago-Navarro, E., Barendregt, A., Heck, A.J.R., Alfonso, C., Díaz-Orejas, R., Nieto, C., Espinosa, M., 2012. The toxin-antitoxin proteins RelBE2Spn of Streptococcus pneumoniae: characterization and association to their DNA target. Proteins. 80, 1834-1846.

Mutschler, H., Meinhart, A., 2011. $\varepsilon / \zeta$ systems: their role in resistance, virulence, and their potential for antibiotic development. J. Mol. Med. 89, 1183-1194.

Nieto, C., Pellicer, T., Balsa, D., Christensen, S.K., Gerdes, K., Espinosa, M., 2006. The chromosomal relBE2 toxin-antitoxin locus of Streptococcus pneumoniae: characterization and use of a bioluminescence resonance energy transfer assay to detect toxin-antitoxin interaction. Mol. Microbiol. 59, 1280-1296.

Pandey, D.P., Gerdes, K., 2005. Toxin-antitoxin loci are highly abundant in free-living but lost from host-associated prokaryotes. Nucleic Acids Res. . 33, 966-976.

Perez-Dorado, I., Campillo, N.E., Monterroso, B., Hesek, D., Lee, M., Paez, J.A., Garcia, P., Martinez-Ripoll, M., Garcia, J.L., Mobashery, S., Menendez, M., Hermoso, J.A., 2007. Elucidation of the molecular recognition of bacterial cell wall by modular pneumococcal phage endolysin Cpl-1. J. Biol. Chem. 282, 24990-24999.

Pluta, R., Boer, D.R., Lorenzo-Díaz, F., Russi, S., Gómez, H., Fernández-López, C., Pérez-Luque, R., Orozco, M., Espinosa, M., Coll, M., 2017. Structural basis of a histidine-DNA nicking/joining mechanism for gene transfer and promiscuous spread of antibiotic resistance. Proc. Natl. Acad. Sci. USA 114, E6526-E6535.

Rost, B., Yachdav, G., Liu, J., 2004. The PredictProtein server. Nucleic Acids Res. 32, W321-326.

Rued, B.E., Alcorlo, M., Edmonds, K.A., Martínez-Caballero, S., Straume, D., Fu, Y., Bruce, K.E., Wu, H., Håvarstein, L.S., Hermoso, J.A., Winkler, M.E., Giedroc, D.P., 2019. Structure of the large extracellular loop of $\mathrm{Fts} X$ and its interaction with the essential peptidoglycan hydrolase PcsB in Streptococcus pneumoniae. mBio. 10, e02622-02618.

Ruiz-Cruz, S., Solano-Collado, V., Espinosa, M., Bravo, A., 2010. Novel plasmid-based genetic tools for the study of promoters and terminators in Streptococcus pneumoniae and Enterococcus faecalis. J. Microbiol. Meth. 83, 156-163.

Studier, F.W., Moffatt, B.A., 1986. Use of bacteriophage T7 RNA polymerase to direct selective high-level expression of cloned genes. J. Mol. Biol. 189, 113-130.

Studier, F.W., Rosenberg, A.H., Dunn, J.J., Dubendorff, J.W., 1990. Use of T7 RNA polymerase to direct expression of cloned genes. Meth. Enzymol. 185, 60-89. 
Tettelin, H., Nelson, K.E., Paulsen, I.T., Eisen, J.A., Read, T.D., Peterson, S., Heidelberg, J., DeBoy, R.T., Haft, D.H., Dodson, R.J., Durkin, A.S., Gwinn, M., Kolonay, J.F., Nelson, W.C., Peterson, J.D., Umayam, L.A., White, O., Salzberg, S.L., Lewis, M.R., Radune, D., Holtzapple, E., Khouri, H., Wolf, A.M., Utterback, T.R., Hansen, C.L., McDonald, L.A., Feldblyum, T.V., Angiuoli, S., Dickinson, T., Hickey, E.K., Holt, I.E., Loftus, B.J., Yang, F., Smith, H.O., Venter, J.C., Dougherty, B.A., Morrison, D.A., Hollingshead, S.K., Fraser, C.M., 2001. Complete genome sequence of a virulent isolate of Streptococcus pneumoniae. Science. 293, 498-506. 
Fabian Lorenzo-Diaz, Inmaculada Moreno-Córdoba and Manuel Espinosa, as authors of the manuscript entitled "Complete labelling of pneumococcal DNA-binding proteins with seleno-L-methionine" declare no conflict of interest. 
- An optimized method for complete SeMet-labelling of DNA-binding proteins is presented.

- Validation of the protocol was performed with two different pneumococcal proteins, which fully retained their activity. 